\title{
O poder tecnológico no mundo atual: implicações e desafios socioambientais
}

\author{
THE TECHNOLOGICAL POWER IN THE CURRENT WORLD: Implications and \\ socio-environmental challenges
}

Francisco de Aquino Júnior*

\begin{abstract}
Resumo
Se a técnica sempre foi um elemento fundamental na vida humana, ela se tornou no mundo moderno-contemporâneo o elemento determinante de nossa vida em todas as suas dimensões, isto é, tornou-se a esfera a partir da qual e em função da qual tudo, do macro ao micro, é pensado e regulado. É isso que o papa Bento XVI chama "horizonte cultural tecnocrático" e o papa Francisco chama "paradigma tecnocrático". O texto faz uma reflexão filosófico-teológica do poder tecnológico no mundo atual a partir de suas implicações e de seus desafios socioambientais. Começa com uma reflexão sobre a importância e o lugar da técnica na vida humana (abordagem antropológica). Apresenta as características fundamentais da técnica moderna a partir de sua relação intrínseca com a ciência e com as forças dominantes da sociedade (relação técnica-ciência-poder). Explicita suas implicações e seus desafios socioambientais (abordagem ética). E conclui com algumas considerações de ordem teológico-pastorais, também a partir de suas implicações e de seus desafios socioambientais (abordagem teológica).
\end{abstract}

Palavras-chave: Tecnologia; Poder; Dominação; Ameaça; Pecado.

\begin{abstract}
If technology has always been a fundamental element in human life, it has become in the moderncontemporary world the determining element of our life in all its dimensions, that is, it has become the place from which and in function of which everything from macro to micro is thought and regulated. This is what Pope Benedict XVI calls the "technocratic cultural horizon" and Pope Francis calls it the "technocratic paradigm". The text makes a philosophical-theological reflection of technological power in the current world from its implications and its socio-environmental challenges. It begins with a reflection on the importance and place of technology in human life (anthropological approach). It presents the fundamental characteristics of modern technology from its intrinsic relationship with science and with the dominant forces of society (relationship technology-science-power). It finishes with some thoughts of theological-pastoral significance from its implications and its socio-environmental challenges (theological approach).
\end{abstract}

Keywords: Technology; Power; Dominance; Threat; Sin.

Artigo submetido em 17 de março de 2019 e aprovado em 18 de agosto de 2020.

* Doutor em Teologia pela Westfälische Wilhelms Universität Münster. Professor da FCF e da Unicap. País de origem: Brasil. E-mail: axejun@yahoo.com.br 


\section{Introdução}

A técnica é um elemento fundamental na vida humana e está presente em todos os povos e civilizações. Mas ela se tornou no mundo modernocontemporâneo $o$ fator determinante de nossa vida, a ponto de se constituir como a esfera a partir da qual e em função da qual tudo, do macro ao micro, é pensado e regulado. Aquilo que o papa Bento XVI chamava na Encíclica Caritas in veritate "horizonte cultural tecnocrático" (BENTO XVI, 2009, n. 70) e que o papa Francisco chama na Encíclica Laudato si” "paradigma tecnocrático" (FRANCISCO, 2015a, n. 101Ss).

Essa situação exige de nós uma reflexão séria sobre o lugar, a importância, os riscos e os limites da técnica a fim de que, em vez de possibilitar e potencializar a vida humana num equilíbrio socioambiental, não se torne uma ameaça e um fator de destruição da vida humana e do conjunto da vida no planeta. E a Encíclica Laudato si’ do papa Francisco oferece elementos preciosos para essa reflexão: tanto no que diz respeito ao diagnóstico da situação atual, quanto no que se refere aos princípios ético-teológicos de seu discernimento, quanto, ainda, no que diz respeito às opções fundamentais que devem orientar e regular seu desenvolvimento atual.

É nesse contexto e nessa perspectiva que se insere nossa reflexão sobre o poder tecnológico em nossa sociedade: suas implicações e seus desafios socioambientais. Começaremos destacando a importância e o lugar da técnica na vida humana. Chamaremos atenção para a especificidade da técnica no mundo moderno-contemporâneo, bem como para suas implicações e seus desafios socioambientais. E concluiremos com algumas considerações de ordem teológicopastorais.

\section{Importância e lugar da técnica na vida humana}

A técnica é um elemento fundamental e imprescindível na vida humana. Faz parte do modo humano de compensar seus limites biológicos e ampliar seus 
poderes no processo de conquista e efetivação da própria vida. Sem técnica - por mais elementar que seja ou pareça - a vida humana seria simplesmente impossível.

Diferentemente dos demais animais, o animal humano tem que conquistar e fazer a própria vida no sentido mais estrito da palavra. A vida humana é uma tarefa e uma conquista que se efetivam mediante processo permanente de apropriação e criação de "possibilidades" (Cf. ZUBIRI, 2003, p. 15-112, 372ss). Não é algo dado e garantido de uma vez por todas, mas possibilitado, vale a redundância, pelas possibilidades disponíveis em cada tempo e lugar. Mas essas possibilidades sempre limitadas! - só se constituem como tais, enquanto apropriadas e/ou criadas pelo homem para fazer a vida de uma forma ou de outra. A expressão “possibilidades” não deve ser entendida aqui como "aquilo que não é impossível nem sequer como aquilo que é positivamente possível", mas como "aquilo que possibilita", isto é, aquilo que "dá um poder sem dar uma necessidade fixa e unidirecional de realização desse poder" (ELLACURÍA, 1999, p. 521). Diz respeito, em última instância, ao processo de possibilitação da vida humana. E num duplo sentido. É algo processual no sentido de que “cada estágio não só sucede ao anterior, mas se apoia nele" (ZUBIRI, 2006, p. 153). E é algo que se constitui como um "processo de capacitação" na medida em que consiste não simplesmente na produção de um instrumento, mas na "produção do âmbito mesmo do possível” ou num "fazer um poder" (ZUBIRI, 2006, p. 157), isto é, na medida em que "vai incorporando ao sujeito em questão um poder-poder, um poder possibilitar, um poder fazer possível” (ELLACURÍA, 1999, p. 554).

É nesse contexto de efetivação de vida humana mediante processo de apropriação e criação de “possibilidades” que surge e se desenvolve a técnica (Cf. ZUBIRI, 1998, p. 333-341). Ela está essencialmente ligada ao modo humano de se enfrentar com as coisas (possibilidades a serem apropriadas) e de se efetivar como realidade (defesa das ameaças e satisfação das necessidades). Tem a ver, portanto, com o "processo de possibilitação" da vida humana (apropriação e criação de possibilidades), particularmente no que esse processo tem de "capacitação" do homem para fazer a vida ("fazer um poder"). Neste sentido, tem um caráter 
antropológico fundamental. É constitutiva da vida humana: emerge, desenvolve-se e só tem sentido no contexto e em função da realização da vida humana. A técnica não um é fim em si mesma nem vale por si mesma. É algo sempre relativo à vida humana e, como tal, deve ser sempre considerada, desenvolvida e discernida.

E aqui residem a moralidade e teologalidade fundamentais da técnica. Enquanto algo apropriado e/ou criado pelo homem para fazer a vida de uma maneira ou de outra, a técnica nem é algo puramente natural (é sempre algo apropriado e/ou criado pelo homem) nem, consequentemente, é algo ética e teologicamente neutro ou indiferente (possibilita e/ou capacita o homem para fazer a vida de uma determinada maneira). Na medida em que o homem faz a vida, é responsável por ela (moralidade fundamental da vida humana). E a maneira como ele faz a vida pode ser mais ou menos ética e/ou de acordo com a vontade de Deus (eticidade e teologalidade fundamentais da ação humana). De modo que, seja pelo que tem de fruto da ação humana, seja pelo modo de vida que possibilita e/ou capacita, a técnica tem uma dimensão ético-teologal fundamental. Pelo simples fato de que ela não existe por si mesma, mas apenas no contexto de realização da vida humana ou como possibilidade apropriada e/ou criada pelo homem que o capacita para fazer a vida de uma determinada maneira, a técnica jamais pode ser tomada como meio ou instrumento que, em si mesmo, seria ética e teologicamente neutro ou indiferente.

E isso que, de algum modo e em alguma medida, vale para todo tipo de técnica em todos os tempos e culturas, vale de modo particular para a técnica moderno-contemporânea, dados o caráter científico que ela adquiriu, o poder que ela confere ao homem e sua vinculação aos grupos e setores dominantes da sociedade.

\section{A técnica no mundo atual}

Se a técnica sempre foi um elemento fundamental na vida humana, ela se tornou no mundo moderno-contemporâneo o elemento determinante de nossa vida 
em todas as suas dimensões. Como bem afirma Manfredo Oliveira, em nosso mundo, “a técnica não é apenas um fenômeno importante ou um setor específico, mas seu elemento determinante" (OLIVEIRA, 2010a, p. 43). Ela caracteriza “o modo de ser do homem moderno" ou a "forma de nossa civilização" ou a "forma da consciência contemporânea" (Cf. OLIVEIRA, 1990, p. 73-83): “é a atitude fundamental do homem com relação ao seu mundo" (OLIVEIRA, 1990, p. 79s). Trata-se, aqui, de uma "compreensão da realidade que perpassa todas as dimensões da existência do homem em sociedade, até mesmo no campo de sua vida "privada" (OLIVEIRA, 1990, p. 80). Neste sentido, ela se tornou "uma categoria central para compreender o mundo em que vivemos e a postura do ser humano ante a realidade como um todo" (OLIVEIRA, 2010a, p. 39) e, consequentemente, um desafio ético fundamental de nossa época.

Convém considerarmos com mais atenção as características fundamentais dessa técnica que se tornou o elemento fundamental e determinante de nossa vida, bem como as implicações e os desafios socioambientais que ela nos impõe.

\subsection{Características fundamentais}

Se a técnica sempre teve a ver com saber (só um animal inteligente produz técnica) e com poder (possibilita, capacita, empodera o homem), ela se constituiu no mundo moderno-contemporâneo como um saber científico e um saber muito poderoso controlado pelos grupos dominantes da sociedade. É inseparável da ciência moderna e das relações de poder que determinam o desenvolvimento dessa ciência. É uma técnica científica e uma técnica de poder. Um trio inseparável: técnica-ciência-poder.

a) É uma técnica científica. O que caracteriza a técnica moderna é que "ela se fez ciência, ou seja, se baseia num conhecimento rigoroso da natureza e de suas leis", constituindo-se como "um saber empírico matematicamente articulado" (OLIVEIRA, 2010a, p. 50) que tem como objetivo básico "articular um conhecimento que torne eficaz a intervenção do ser humano no seu mundo" 
(OLIVEIRA, 2010a, p. 53; Cf. 1990). Trata-se, aqui, de um "conhecimento rigoroso" (ciência) em vista de uma intervenção "eficaz" no mundo (dominação). E isso não só aumentou enormemente sua eficácia e foi atingindo e dominando todos os âmbitos da natureza e da própria vida humana (tipo de conhecimento), mas foi configurando e impondo um tipo de técnica que se tornou fator determinante da civilização atual (objetivo básico).

Na linguagem simples e direta do Papa Francisco em sua Encíclica Laudato si', trata-se, aqui, de uma "técnica de posse, domínio e transformação" que reduz a relação homem-mundo à relação sujeito-objeto, reduz tudo a objeto, isto é, a "realidade informe totalmente disponível para a manipulação", fragmenta a realidade e perde a visão de conjunto da mesma com enormes consequências para a vida humana tanto em seu aspecto práxico quanto em seu aspecto teórico (FRANCISCO, 2015a, n. 106-110). É verdade que o homem sempre interveio na natureza, apropriando-se dela como possibilidade para fazer a vida. Mas agora, graças ao poder da técnica aliada à ciência moderna, diz Francisco, "o que interessa é extrair o máximo possível das coisas por imposição da mão humana, que tende a ignorar ou esquecer a realidade própria do que tem à sua frente”. A isto está ligada a "ideia de um crescimento infinito ou ilimitado", que supõe a "mentira da disponibilidade infinita dos bens do planeta, o que leva a 'espremê-lo' até ao limite e para além do mesmo" (FRANCISCO, 2015a, n. 106). E disso não escapa nem o ser humano como comprovam as experiências com embriões, o controle do comportamento humano com agentes químicos e a manipulação dos processos genéticos (Cf. OLIVEIRA, 2010a, p. 48s).

b) É uma técnica de poder. A técnica sempre teve a ver com poder (possibilita, capacita, empodera) e sempre foi fator de dominação (controle, domínio, imposição). Mas ela adquiriu no mundo moderno um poder impressionante que se expandiu sobre todos os âmbitos da vida e que é capaz de destruir o conjunto da vida no planeta. Trata-se de um poder universal, no sentido de que "a totalidade da experiência humana é marcada pela técnica, as formas de pensar e de agir, chegando até aos espaços mais familiares e privados da vida, os 
hábitos e costumes, as instituições e os valores" (OLIVEIRA, 2010a, p. 43). Trata-se de um poder ameaçador, na medida em que "a humanidade de hoje tem consciência de possuir todos os meios técnico-científicos para a extinção de si mesma e de todas as outras formas de vida sobre o planeta” e, mesmo assim, tem se mostrado incapaz de pôr fim a esse processo ou ao menos reduzir seu ritmo (OLIVEIRA, 2010a, p. 40s). E trata-se, por fim, o que é ainda mais grave, de um poder controlado pelos grandes grupos econômicos. Todo esse processo de desenvolvimento científico-tecnológico, inclusive as chamadas biotecnologias, está vinculado a "negócios financeiros gigantescos como o patenteamento de genes e a produção de órgãos para transplantes” (OLIVEIRA, 2010a, p. 47s).

Como bem reconhece o Papa Francisco na Encíclica Laudato si’, todo esse desenvolvimento científico-tecnológico confere à humanidade hoje um "poder tremendo", ou melhor, confere "àqueles que detêm o conhecimento e, sobretudo, o poder econômico para desfrutá-lo, um domínio impressionante sobre o conjunto do gênero humano e do mundo inteiro". E continua: "nunca a humanidade teve tanto poder sobre si mesma”, mas "nada garante que o utilizará bem, sobretudo se se considera a maneira como o está fazendo" (FRANCISCO, 2015a, n. 104). Não se trata simplesmente de um crescimento gigantesco de poder sobre o conjunto da realidade, o que já seria preocupante, mas se trata, sobretudo, do controle desse poder pelos grandes grupos econômicos e de sua subordinação total a seus interesses econômicos, mesmo que com altíssimos custos socioambientais como demonstram, por exemplo, o lançamento de bombas atômicas sobre Hiroshima e Nagasaki durante a segunda guerra mundial e os crimes recentes das mineradoras em Mariana e Brumadinho.

c) Técnica-ciência-poder. Essa relação e/ou identificação técnica-ciênciapoder caracteriza a técnica atual e constitui aquilo que o papa Francisco chama “paradigma tecnocrático" que está na raiz da crise ecológica que caracteriza nosso tempo (FRANCISCO, 2015a, n. 101; Cf. OLIVEIRA, 2016, p. 129-145). Ele diz respeito ao "modo como a humanidade assumiu a tecnologia e o seu desenvolvimento" e se constitui como "um paradigma homogêneo e 
unidimensional" (FRANCISCO, 2015a, n. 106). Francisco insiste que "é preciso reconhecer que os produtos da técnica não são neutros porque criam uma trama que acaba por condicionar os estilos de vida e orientam as possibilidades sociais na linha dos interesses de determinados grupos de poder”. Mesmo “certas opções que parecem puramente instrumentais, na realidade são opções sobre o tipo de vida social que se pretende desenvolver" (FRANCISCO, 2015a, n. 107). E esse paradigma "tende a exercer o seu domínio sobre a economia e a política" que assumem "todo o desenvolvimento tecnológico em função do lucro" (FRANCISCO, 2015a, n. 109), bem como sobre a forma de "saber" que cada vez mais se constitui e se desenvolve como um saber especializado e fragmentado incapaz de uma visão e compreensão mais integrais da realidade (Cf. FRANCISCO, 2015a, n. 110-112). Nesse sentido, constitui-se como um “paradigma unidimensional” (FRANCISCO, 2015a, n. 106): reduz tudo a objeto ou recurso, reduz a razão a um saber técnicoinstrumental, põe como objetivo fundamental da vida humana o acúmulo de bens e poder e acaba reduzindo a totalidade da realidade ao físico ou à matéria - uma espécie “fisicalismo" ou "materialismo metafísico" (Cf. OLIVEIRA, 2017, p. 545571).

\subsection{Implicações e desafios socioambientais}

Tudo isso tem enormes consequências socioambientais e impõe-se como desafio ético fundamental de nossa hora histórica. Está em jogo, aqui, a vida das maiorias pobres e marginalizadas de nossas sociedades e, mesmo, o futuro da vida no planeta. E isso exige de nós discernimento ético e engajamento social. Não podemos naturalizar o desenvolvimento técnico-científico em curso (é fruto de opção) nem tomá-lo como algo moralmente neutro ou indiferente (está a serviço de interesses bem concretos).

Certamente, "ninguém quer o regresso à Idade da Pedra, mas é indispensável abrandar a marcha para olhar a realidade de outra forma, recolher os avanços positivos e sustentáveis e ao mesmo tempo recuperar os valores e os grandes objetivos arrasados por um desenfreamento megalômano" (FRANCISCO, 
2015a, n. 114). De modo que não se trata de condenação nem rejeição da técnica, o que seria um absurdo, mas de uma avaliação crítica sobre o tipo de tecnologia que vem sendo desenvolvido nos últimos séculos a partir de suas consequências negativas socioambientais e dos reais interesses a que serve.

E, aqui, é preciso começar reconhecendo que o "poder da tecnologia nos põe diante de uma encruzilhada" (FRANCISCO, 2015a, n. 102). Por um lado, trouxe beneficios enormes para a humanidade: na produção, no transporte, na medicina, na engenharia, na comunicação, no lazer etc. Como não reconhecer que isso significou um aumento da qualidade de vida e alargou enormemente as possibilidades de vida da humanidade? E esse desenvolvimento tecnológico é tão determinante de nosso modo de vida, que é difícil, para não dizer impossível, pensar a vida humana em nossa sociedade prescindindo dele. Mas, por outro lado, trouxe enormes problemas para a humanidade: aprofundou as desigualdades sociais; possibilitou novas formas de extermínio em massa nos campos de concentração, nos conflitos e nas guerras; aumentou enormemente o poder de dominação dos países e grupos mais ricos; possibilitou um processo de globalização do mundo segundo a lógica do mercado; produziu, enfim, a crise ecológica em que estamos mergulhados que tem consequências imediatas trágicas para as populações pobres e marginalizadas, que compromete a qualidade de vida das futuras gerações e põe em risco o conjunto da vida no planeta.

A ambiguidade ou contradição fundamental do desenvolvimento tecnológico em curso revela-se no fato de que, embora tenha todos os meios necessários para eliminar a fome e a miséria no mundo, não só não o tenha feito, mas, ao contrário, tenha favorecido o aumento das desigualdades sociais. Sem falar no desenvolvimento de um modo de produção que atenta contra a biodiversidade e o equilíbrio socioambiental e põe em risco o conjunto da vida no planeta. Aquilo que Manfredo Oliveira qualifica como a “problemática básica” da civilização técnicocientífica: "a incapacidade estrondosa do ser humano de pôr um fim ao processo previsivelmente destrutivo de si mesmo e da natureza” (OLIVEIRA, 2010a, p. 40). Com o agravante de tudo isso ser pensado e desenvolvido a partir e em função de 
interesses econômicos. O sociólogo Boaventura de Sousa Santos fala, aqui, do "fenômeno global da industrialização da ciência” que se desenvolveu, sobretudo, a partir das décadas de trinta e quarenta e que "acarretou o compromisso desta com os centros de poder econômico, social e político, os quais passaram a ter um papel decisivo na definição das prioridades científicas” (SANTOS, 2010, p. 56s). É neste contexto que a tecnologia se tornou um problema ético fundamental para nossas sociedades (Cf. OLIVEIRA, 2010b, 9-38).

Um nome importante nesse debate é, sem dúvida nenhuma, o filósofo judeu alemão Hans Jonas (JONAS, 2006; 2013; OLIVEIRA, J, 2014; OLIVEIRA MORETTO - SGANZERLA, 2015). Partindo de uma análise da "técnica moderna" e de seus impactos na vida humana e no conjunto do planeta (JONAS, 2013, p. 2561), ensaia uma "ética para a civilização tecnológica", baseada no "princípio responsabilidade". Desenvolvida segundo o "ideal baconiano" ou o "programa baconiano" de "colocar o saber a serviço da dominação da natureza e utilizá-la para melhorar a sorte da humanidade” (JONAS, 2006, p. 235), a técnica moderna foi expandindo seu poder sobre todos os âmbitos da natureza e da própria vida humana (JONAS, 2013, p. 40-50) e impondo seu dinamismo compulsivo de poder e dominação, a ponto de adquirir autonomia em relação ao homem e tornar-se uma “ameaça tenebrosa” para a própria vida humana. Nas palavras de Jonas, “o poder tornou-se autônomo, enquanto sua promessa transformou-se em ameaça e sua perspectiva de salvação, em apocalipse”. E isso impõe a necessidade de "um poder [não técnico] sobre o poder [técnico]" (JONAS, 2006, p. 236). É nesse contexto que Jonas vai desenvolver sua ética da responsabilidade: "uma ética que, por meio de freios voluntários, impeça o poder dos homens de se transformar em uma desgraça para eles mesmos" (JONAS, 2006, 211); uma ética que se enfrente criticamente com o "ideal utópico" da civilização tecnológica (Cf. JONAS, 2006, p. 22s), contrapondo à "imodéstia de seus objetivos" a "tarefa mais modesta que obriga ao temor e ao respeito: conservar incólume para o homem [...] seu mundo e sua essência contra os abusos de seu poder" (JONAS, 2006, p. 23); uma ética que considere os "efeitos de longo prazo" da ação técnica e que leve a sério o "dever para com o futuro" ("ética do futuro"), que desenvolva a capacidade de previsão dos 
perigos e dê "primazia ao mau prognóstico sobre o bom" ("heurística do temor"1) e se constitua como responsabilidade atual em relação ao futuro ("princípio responsabilidade" (JONAS, 2006, p. 67-97)).

Entre nós, na América Latina, Ignacio Ellacuría, filósofo-teólogo, mártir salvadorenho, enfrentou-se com a problemática do "conceito filosófico de tecnologia apropriada" (ELLACURÍA, 2001, p. 227-250). Começa com uma reflexão sobre "o que é a técnica" (conceito filosófico de técnica) e conclui indicando algumas características de uma tecnologia apropriada (conceito filosófico de tecnologia apropriada). Ele parte do fato de que "o homem é uma realidade-no-mundo, de tal modo que o mundo é parte integrante do existir humano" (ELLACURÍA, 2001, p. 230) e da constatação de “o mundo em que vivemos atualmente já não é o mundo natural”, mas "um mundo profundamente transformado pelo homem” (ELLACURÍA, 2001, p. 231). Cada vez mais, a técnica se constitui como "princípio criador de nosso mundo e, através dele, de nosso existir humano" (ELLACURÍA, 2001, p. 232). Mas um princípio "profundamente ambivalente" (destruição X salvação, vida X morte) e que, por isso mesmo, exige reflexão e discernimento sobre a "técnica apropriada” (ELLACURÍA, 2001, p. 233). E isso é um problema "científico", "político" (Cf. ELLACURÍA, 2001, p. 241) e “ético" (ELLACURÍA, 2001, p. 248). Diz respeito tanto aos "meios" (técnicos), quanto aos "fins" (éticos): "Não há uma tecnologia tecnicamente boa se não é, ao mesmo tempo, eticamente boa" (ELLACURÍA, 2001, p. 248). Ellacuría conclui sua reflexão indicando três critérios para se falar de uma tecnologia boa ou apropriada: 1) Deve ser "o mais racional possível”, no sentido de ser "o mais eficaz para resolver o problema proposto" ou da "melhor acomodação dos meios aos fins" ("princípio da racionalidade") (ELLACURÍA, 2001, p. 248s); 2) Como a técnica envolve “opção” e pode ser “princípio de dominação e de libertação, princípio de alienação e de humanização", é preciso “optar pela libertação e pela humanização” ("tecnologia

\footnotetext{
${ }^{1}$ Como bem observou Jelson Oliveira, o termo alemão Furcht (Heuristik der Furcht) é mais adequadamente traduzido por temor que por medo. "A palavra medo tem uma conotação negativa na língua portuguesa que não traduz bem o alemão Furcht, cujo termo seria melhor traduzido por temor, por transmitir a ideia não de um sentimento passivo, mas de um receio fundado, de um medo acompanhado de respeito frente à força do mal eminente, de escrúpulo e zelo que promovem a precaução; e menos com a perturbação mental provocada por algo estranho e perigoso (patologia), como um sentimento desagradável diante do desconhecido" (OLIVEIRA, 2014, p. 129, nota 22).
} 
libertadora") (ELLACURÍA, 2001, p. 249); 3) Finalmente, "o critério das maiorias" ou o "ponto de vista das maiorias oprimidas": "em uma sociedade dividida não é possível encontrar o bem comum senão a partir da perspectiva das maiorias"; “o bem comum só se consegue mirando às maiorias e procurando para elas as melhores soluções" ("critério das maiorias") (ELLACURÍA, 2001, p. 249s).

Na medida em que "a técnica é um exercício da ação humana, isto é, uma forma de ação" e que "toda forma de ação está sujeita a uma avaliação moral”, ela é um problema ético e deve ser submetida a considerações éticas (JONAS, 2013, p. 51). E na medida em que a tecnologia moderna "avança sobre quase tudo que diz respeito aos homens", convertendo-se em um "problema tanto central quanto premente de toda existência humana sobre a terra" (JONAS, 2013, p. 25) e até mesmo em uma "ameaça tenebrosa" para a vida no planeta (Cf. JONAS, 2006, p. 235), ela se impõe como um problema ético fundamental em nosso tempo.

\section{A modo de conclusão: considerações teológico-pastorais}

É importante ter presente que toda essa problemática da tecnologia moderna, explicitada a partir de suas implicações e de seus desafios socioambientais, não é apenas uma questão ética que diz respeito ao sentido e às implicações socioambientais da ação humana no mundo, mas é também, e em última instância, uma questão espiritual que diz respeito, positiva e/ou negativamente, à nossa relação com Deus. Por isso, não basta uma consideração

ético-filosófica da tecnologia moderna. É preciso avançar na direção de uma consideração teológico-pastoral que, embora supondo e apoiando-se em uma consideração ético-filosófica, não se identifica sem mais com ela, mas trata de explicitar sua dimensão estritamente teologal ou espiritual. Neste sentido, assumindo uma intuição de Victor Codina, queremos insistir em que "é necessário fazer uma bioteologia, não só uma bioética” (CODINA, 2013, p. 319). Passar (ir além) de uma "bioética" para uma "bioteologia". 
E uma consideração teológico-pastoral da tecnologia moderna consiste em uma avaliação ou em um discernimento dessa tecnologia (suas características, seu dinamismo, suas implicações socioambientais) a partir e em função do desígnio de Deus para a humanidade, tal como foi revelado na história de Israel e definitivamente na vida de Jesus de Nazaré. Avaliação ou discernimento sempre em vista da ação dos cristãos no mundo: ação que se vive na comunhão com Deus, ação conduzida e dinamizada pelo Espírito de Deus, ação por meio da qual Deus vai realizando seu desígnio salvífico (Cf. AQUINO JÚNIOR, 2011, p. 143-172; 2016, p. 24-40).

No contexto da crise ecológica atual que tem como "raiz" precisamente o "paradigma tecnocrático" e o "antropocentrismo moderno" (FRANCISCO, 2015a, n. 101-136), Francisco fala do desígnio salvífico de Deus em termos de "Evangelho da criação" (FRANCISCO, 2015a, n. 62-100). Trata-se de um evangelho eco-social que diz respeito a toda a criação e, nela, de modo particular, à criatura humana. $\mathrm{E}$ um evangelho que, especialmente no contexto de crise em que vivemos, apresentase como uma Boa Notícia para a humanidade. Segundo este evangelho, todos os seres são criaturas de Deus, expressão de seu amor, manifestação de sua glória e, portanto, muito mais que meros recursos, meios ou instrumentos e a criatura humana tem uma "especial dignidade" que implica uma "tremenda responsabilidade" com o conjunto da criação. De modo que ofender a criação e particularmente a criatura humana é ofender a Deus e cuidar da criação, em especial da vida humana, é colaborar com a obra salvífico-criadora de Deus, assumindo a tarefa que ele nos confiou.

Sendo a criatura humana parte da criação e corresponsável por ela, sua ação, que tem sempre e cada vez mais uma dimensão tecnológica, deve ser dinamizada, efetivada e discernida a partir e em função do cuidado da criação. Tudo que atenta contra a criação em geral e a criatura humana em particular atenta contra a obra criadora e o desígnio salvífico de Deus e se constitui em sentido estrito e objetivo (para além da consciência e das boas intensões) como pecado. E tudo que favorece, protege e defende o desenvolvimento integral da criação e, em particular, da 
criatura humana toma parte e colabora na obra criadora e no desígnio salvífico de Deus e, assim, constitui-se em sentido estrito e objetivo (para além da consciência) como mediação de salvação no mundo. É a dimensão teologal da ação humana em seu caráter pecaminoso ou salvífico que precisa ser sempre discernida em cada tempo e em cada situação.

É nesse horizonte e nessa perspectiva que a tecnologia moderna precisa ser considerada. Ela deve ser pensada, dinamizada e desenvolvida em função do cuidado da criação que constitui a vocação fundamental do ser humano e determina seu lugar no conjunto da criação. Na medida em que ela se constituiu como poder de dominação e como ameaça sobre o conjunto da criação, constitui-se como um poder pecaminoso que atenta contra a obra criadora e o desígnio salvífico de Deus no mundo. Nesse contexto, a fé cristã se efetiva como reação teórica e práxica a esse tipo pecaminoso de tecnologia (aspecto crítico-profético da fé) e como busca, ensaio e promoção de uma tecnologia voltada para o cuidado da criação (aspecto profético-criativo da fé).

E aqui se pode compreender tanto a crítica feita por Francisco ao modelo hegemônico de desenvolvimento tecnológico no mundo atual, quanto seu interesse, seu apreço e seu apoio aos movimentos populares na luta pelos direitos das maiorias populares e na construção de alternativas. Na Encíclica Laudato Si’, ele insiste que nós "temos de nos convencer que, reduzir um determinado ritmo de produção e consumo, pode dar lugar a outra modalidade de progresso e desenvolvimento"; que é preciso "abrir caminhos a oportunidades diferentes, que não implicam frenar a criatividade humana nem seu sonho de progresso, mas orientar esta energia por novos canais" (FRANCISCO, 2015a, n. 191); que, "face ao crescimento ganancioso e irresponsável", devemos pensar, inclusive, em "diminuir um pouco a marcha, pôr alguns limites razoáveis e até mesmo retroceder antes que seja tarde" (FRANCISCO, 2015a, n. 193); enfim, que "a rentabilidade não pode ser o único critério a ter em conta” na avaliação de uma inovação tecnológica” (FRANCISCO, 2015a, n. 187). E busca discernir sinais e indícios de novidade ou alternativa no mundo, não obstante seus limites e suas ambiguidades 
(FRANCISCO, 2015a, n. 26, 34, 35, 37, 54, 55, 58, 111, 112, 167, 168, 1169, 179, 180, 206, 211), sem, contudo, iludir-se com soluções aparentes ou cínicas (FRANCISCO, 2015a, n. 170, 171, 194, 197). Também nos encontros com os movimentos populares, Francisco denuncia o sistema econômico-tecnológico atual como ídolo/idolatria que atenta "contra o projeto de Jesus" e insiste na importância da solidariedade entre os pobres, das alternativas (também técnicas) que vão criando e ensaiando nas bases e de seu potencial transformador, bem como na sua importância como força social no processo de transformação da sociedade. Os movimentos populares são "como uma benção para a humanidade" (Cf. FRANCISCO, 2015b, 2015c, 2016; AQUINO JÚNIOR, 2018; AQUINO JÚNIOR; ABDALLA; SÁVIO, 2018).

Podemos identificar a partir da Encíclica Laudato Si’ e dos encontros com os movimentos populares três orientações pastorais que se implicam e se complementam: 1) crítica e denúncia do modelo tecnológico hegemônico na medida em que atenta contra a obra criadora e o desígnio salvífico de Deus e se constitui como pecado; 2) apoio e fortalecimento das alternativas tecnológicas dinamizadas pela lógica do cuidado da criação na medida em que se constituem como mediação salvífica; 3) tudo isso a partir das vítimas, de suas lutas e de suas organizações que são “como uma benção para a humanidade” e são, por excelência, lugar da ação do Espírito de Deus que, como afirma Codina, “atua a partir de baixo” (Cf. CODINA, 2015).

Importa, aqui, insistir que nada disso é indiferente à fé cristã enquanto um modo de vida dinamizado pelo Espírito que nos faz assumir a vocação e missão de “cuidado da criação”, começando pelas principais vítimas que são os pobres e marginalizados. Nisso também se joga a eficácia e relevância da fé em seu caráter de fermento, sal, luz, semente do reinado de Deus. As vítimas desse mundo tecnocrático são, n’Ele, juízes e senhores de nossa vida, de nossa fé (Cf. Lc 10, 2537; Mt 25, 31-46). 


\section{REFERÊNCIAS}

AQUINO JÙNIOR, Francisco de; ABDALLA, Maurício; SÁVIO, Robson (orgs.). Papa Francisco com os movimentos populares. São Paulo: Paulinas, 2018.

AQUINO JÚNIOR, Francisco. “'A humanidade/criação geme com dores de parto’. Dimensão socioambiental do reinado de Deus”. In: A dimensão socioestrutural do reinado de Deus: Escritos de teologia social. São Paulo: Paulinas, 2011, p. 143-172.

AQUINO JÚNIOR, Francisco. "Fé cristã e superação da crise ecológica: Abordagem teológica”. In: MURAD, Afonso; TAVARES, Sinivaldo Silva (orgs.). Cuidar da casa comum: Chaves de leitura teológicas e pastorais da Laudato si’. São Paulo: Paulinas, 2016, p. 24-40.

AQUINO JÚNIOR, Francisco. Organizações populares. São Paulo: Paulinas, 2018.

BENTO XVI. Carta Encíclica Caritas in Veritate sobre o desenvolvimento humano integral na caridade e na verdad $e$. São Paulo: Paulinas, 2009.

BÍBLIA DE JERUSALÉM. Edição revista e ampliada. São Paulo: Paulus, 2002.

CODINA, Victor. Diario de un teólogo del posconcilio: Entre Europa y América Latina. Bogotá: San Pablo, 2013.

CODINA, Victor. El Espíritu del Señor actúa desde abajo. Maliaño: Sal Terrae, 2015.

ELLACURÍA, Ignacio. "El concepto filosófico de tecnología apropriada”. Escritos Filosóficos III. San Salvador: UCA, 2001, p. 227-250.

ELLACURÍA, Ignacio. Filosofía de la realidad histórica. San Salvador: UCA, 1999.

FRANCISCO. Carta Encíclica Laudato si' sobre o cuidado da casa comum. São Paulo: Paulinas, 2015.

FRANCISCO. Discurso do Papa Francisco aos participantes do Encontro Mundial dos Movimentos Populares. Brasília: CNBB, 2015.

FRANCISCO. Discurso do Papa Francisco aos participantes do III Encontro Mundial dos Movimentos Populares. Brasília: CNBB, 2016.

FRANCISCO. Discurso do Papa Francisco no II Encontro Mundial dos Movimentos Populares. Brasília: CNBB, 2015.

JONAS, Hans. O princípio responsabilidade: Ensaio de uma ética para a civilização tecnológica. Rio de Janeiro: Contraponto/PUC-Rio, 2006.

JONAS, Hans. Técnica, medicina e ética: Sobre a prática do princípio responsabilidade. São Paulo: Paulus, 2013. 
OLIVEIRA, Jelson. Compreender Hans Jonas. Petrópolis: Vozes, 2014.

OLIVEIRA, Jelson; MORETTO, Geovani; SGANZERLA, Anor. Vida, técnica e

responsabilidade: Três ensaios sobre a filosofia de Hans Jonas. São Paulo: Paulus, 2015.

OLIVEIRA, Manfredo Araújo de. "Ética e técnica”. In: Ética, direito e democracia. São Paulo: Paulus, 2010, p. 39-76.

OLIVEIRA, Manfredo Araújo de. “O paradigma tecnocrático”. In: MURAD, Afonso;

TAVARES, Sinivaldo Silva (orgs.). Cuidar da casa comum: Chaves de leitura teológicas e pastorais da Laudato si’. São Paulo: Paulinas, 2016, p 129-145.

OLIVEIRA, Manfredo Araújo de. "O positivismo tecnológico como 'forma da consciência contemporânea”. In: A filosofia na crise da modernidade. São Paulo: Loyola, 1990, p. 73-83.

OLIVEIRA, Manfredo Araújo de. “Os desafios da ética contemporânea”. In: Ética, direito e democracia. São Paulo: Paulus, 2010, p. 9-38.

SANTOS, Boaventura de Sousa. Um discurso sobre as ciências. São Paulo: Cortez, 2010.

ZUBIRI, Xavier. El hombre y Dios. Madrid: Alianza Editorial, 2003.

ZUBIRI, Xavier. Sobre el hombre. Madrid: Alianza Editorial, 1998.

ZUBIRI, Xavier. Tres dimensiones del ser humano: individual, social histórica. Madrid: Alianza Editorial, 2006. 